University of Nebraska - Lincoln

DigitalCommons@University of Nebraska - Lincoln

4-1-1999

\title{
Hydrogen bonding and cooperative effects in mixed dimers and trimers of methanol and trifluoromethanol: An ab initio study
}

\author{
Ruben D. Parra \\ University of Nebraska-Lincoln, rparra1@depaul.edu \\ Xiao Cheng Zeng \\ University of Nebraska-Lincoln, xzeng1@unl.edu
}

Part of the Chemistry Commons

Parra, Ruben D. and Zeng, Xiao Cheng, "Hydrogen bonding and cooperative effects in mixed dimers and trimers of methanol and trifluoromethanol: An ab initio study" (1999). Xiao Cheng Zeng Publications. 59. https://digitalcommons.unl.edu/chemzeng/59 


\title{
Hydrogen bonding and cooperative effects in mixed dimers and trimers of methanol and trifluoromethanol: An ab initio study
}

\author{
Rubén D. Parra and X. C. Zeng \\ Department of Chemistry and Center for Materials Research and Analysis, University of Nebraska-Lincoln, \\ Lincoln, Nebraska 68588
}

(Received 13 August 1998; accepted 5 January 1999)

\begin{abstract}
$A b$ initio calculations are used to provide information on the mixed dimers and cyclic trimers of the methanol-trifluoromethanol system. In order to better understand the systems, the monomers and their corresponding dimers and trimers are also investigated. Molecular structures and harmonic frequencies are obtained at the $\mathrm{B} 3 \mathrm{LYP} / 6-311++\mathrm{G}(d, p)$ level. Interaction energies are calculated with the MP2 and B3LYP methods using the 6-311++ $\mathrm{G}(d, p), 6-311++\mathrm{G}(2 d, 2 p)$, and $6-311++\mathrm{G}(3 d, 2 p)$ basis sets for the dimers and heterodimers. The 6-311+ $+\mathrm{G}(d, p)$ basis set was used to calculate the interaction energies for the trimers and heterotrimers. Because the primary goal of this study is to examine cooperative effects, particular attention is given to parameters such as O...O distances, electronic charge densities at the bond critical points, enhanced dipole moments, shifts in the stretching frequencies of the donor $\mathrm{O}-\mathrm{H}$ bond, and the length of the donor $\mathrm{O}-\mathrm{H}$ bond.

(C) 1999 American Institute of Physics. [S0021-9606(99)30613-9]
\end{abstract}

\section{INTRODUCTION}

Hydrogen bonding plays a significant role in a wide range of chemical and biological processes. ${ }^{1,2}$ The hydrogen bond (HB) is typically defined as an attractive interaction between a proton donor $\mathrm{D}-\mathrm{H}$ and a proton acceptor $\mathrm{A}$ in the same or in a different molecule,

D-H...A,

where $\mathrm{D}$ and $\mathrm{A}$ are normally electronegative atoms such as $\mathrm{N}, \mathrm{O}$, or $\mathrm{F}$. The magnitude of the interaction ranges between 2 and $20 \mathrm{kcal} / \mathrm{mol}$. An important structural characteristic of a hydrogen bond is a shortening of the D...A distance along with a stretching of the $\mathrm{D}-\mathrm{H}$ bond. The amount of these geometrical changes is usually correlated with the strength of the interaction.

A very relevant concept associated with hydrogen bonding is cooperativity, considered as the enhancement of a $\mathrm{HB}$ by the formation of another $\mathrm{HB}$ with either the donor or acceptor of the first $\mathrm{HB} .{ }^{3}$ Cooperativity is frequently applied in theoretical work and for the interpretation of experimental data. ${ }^{4}$ It helps explain the behavior of hydrogen bonded systems.

Alcohols possess the ability to form clusters (selfassociation) in the liquid phase via hydrogen bonding. ${ }^{5}$ Theoretical calculations have been supportive of this picture. ${ }^{6-16}$ Of particular interest are the recent studies of the structural and energetic properties of hydrogen-bonded water, ${ }^{7,8}$ methanol, ${ }^{9-14}$ and water-methanol complexes. ${ }^{15,16}$ It has been found that the dimers have linear hydrogen-bonded structures, while the results for higher oligomers are consistent with cyclic structures. Less attention has been paid to the hydrogen-bonded complexes of perfluoroalcohols. ${ }^{17-23}$

$\mathrm{CF}_{3} \mathrm{OH}$ is the simplest perfluoroalcohol that can be studied by $a b$ initio methods. In addition, it plays an important role in the atmospheric degradation of $\mathrm{CF}_{3} \mathrm{CFH}_{2}$ (HFC-134a) and other hydrofluorocarbons, and is therefore a compound that requires some attention. ${ }^{24-27}$ Our group has recently studied cooperativity effects in cyclic trifluoromethanol trimer at the Hartree-Fock (HF) level and different basis sets. ${ }^{23}$ In contrast to the linear structure of the methanol dimer, we found that the analogous dimer of $\mathrm{CF}_{3} \mathrm{OH}$ involves a secondary hydrogen bond between one of the fluorine atoms of the donor and the hydrogen atom of the acceptor molecule.

From a fundamental standpoint, it appears interesting to study the nature of alcohol-perfluoroalcohol interactions since such study can contribute to the current understanding of the proton-donor (acid) and proton-acceptor (base) character of alcohols and perfluoroalcohols. It is well known that methanol behaves like a bifunctional molecule since it can behave both as a proton donor and as a proton acceptor simultaneously. ${ }^{9-14}$ On the other hand, the proton-acceptor character of $\mathrm{CF}_{3} \mathrm{OH}$ is very weak because the $\mathrm{CF}_{3}$ group removes electron density from the $\mathrm{OH}$ group, so that the extent of self-association is expected to be relatively small; however, the increased acidic property of trifluoromethanol makes it an excellent candidate as a proton donor in the studies of hydrogen-bonded systems.

The purpose of this work is to investigate the hydrogenbonding interactions and cooperativity in the dimers and trimers as well as in the mixed dimers and trimers of methanol and trifluoromethanol molecules.

As an aid in referring to the various structures studied, the following shorthand notation will be used. For the methanol and trifluoromethanol monomers we will use the symbols $\mathrm{M}$ and $\mathrm{T}$, respectively. For the dimers and trimers we will use the notation $\mathrm{T}_{n}$ and $\mathrm{M}_{n}, n=2,3$. For the mixed dimers we have two possibilities, TM and MT. In each case, the first symbol corresponds to the donor, while the second to the acceptor moiety. For the mixed trimers, $\mathrm{T}_{2} \mathrm{M}$ represents a cyclic trimer with two $\mathrm{CF}_{3} \mathrm{OH}$ units and one $\mathrm{CH}_{3} \mathrm{OH}$ unit, 
whereas $\mathrm{M}_{2} \mathrm{~T}$ stands for a cyclic trimer with two $\mathrm{CH}_{3} \mathrm{OH}$ molecules and one $\mathrm{CF}_{3} \mathrm{OH}$ molecule.

\section{COMPUTATIONAL DETAILS}

All $a b$ initio density functional results were calculated using the GAUSSIAN 94 program. $^{28}$ The MP2 calculations were carried out with the GAUSSIAN 98 program. ${ }^{29}$ We used the Becke3LYP nonlocal exchange correlation functional, ${ }^{30}$ which has been extensively used in studies of hydrogenbonded clusters and tested against MP2, MP4, and G2 $a b$ initio calculations. ${ }^{13,14,31-38}$ See for instance Novoa and Sosa. ${ }^{36}$ These authors found that the B3LYP functional predicts hydrogen-bonding geometries that are in very good agreement with MP2 geometries. See also the very relevant paper of Hagemeister et al. ${ }^{14}$ and that of Mó et al. ${ }^{13}$ These researchers have used the B3LYP functional to study methanol clusters. In particular Mó et al. have found that the B3LYP/6-311+ $\mathrm{G}(d, p)$ optimized geometries are not significantly different from the MP2 optimized geometries.

However, Novoa and $\mathrm{Sosa}^{36}$ have shown that density functional theory (DFT) is not a good model for the study of the energetics of hydrogen-bonded complexes. To illustrate this, one can look at the interaction energies for the $\mathrm{H}_{2} \mathrm{O}-\mathrm{H}_{2} \mathrm{O}, \mathrm{NH}_{3}-\mathrm{NH}_{3}$, and $\mathrm{C}_{2} \mathrm{H}_{2}-\mathrm{H}_{2} \mathrm{O}$ systems in the work by Novoa and Sosa. ${ }^{36}$ The counterpoise corrected interaction energies were calculated by the authors using the different basis sets cc-pVDZ, $6-31++\mathrm{G}(2 d, 2 p)$, aug-cc-pVTZ at the HF, MP2, and B3LYP levels. These energies can be used to determine the correlation contribution from the MP2 and the B3LYP models. For the dimer of water, it is found that the B3LYP model estimates a correlation contribution which is nearly independent of the basis set. For the $\mathrm{NH}_{3}$ dimer, the B3LYP model underestimates the correlation contribution by more than a factor of 2. For the $\mathrm{C}_{2} \mathrm{H}_{2}-\mathrm{H}_{2} \mathrm{O}$ system the situation is even worse.

In this work, the interaction energies are calculated at the MP2/6-311 $++\mathrm{G}(d, p)$ level for the trimers and mixed trimers of methanol and trifluoromethanol. For the dimers and mixed dimers, the interaction energies are calculated with the MP2 and the B3LYP models using the $6-311++\mathrm{G}(d, p)$, $6-311++\mathrm{G}(2 d, 2 p)$, and $6-311++\mathrm{G}(3 d, 2 p)$ basis sets. We investigate whether our results of the DFT-B3LYP model with respect to the correlation contribution to the interaction energies parallel those of Novoa and Sosa. ${ }^{36}$

The geometries of the different systems under investigation were optimized at the B3LYP/6-311++ $\mathrm{G}(d, p)$ level. The so optimized geometries were used to obtain the harmonic vibrational frequencies at the same level of theory. These harmonic frequencies were scaled by an empirical factor of $0.98^{39}$ and the scaled frequencies were used to evaluate zero-point energy (ZPE) and thermal corrections to the interaction energies. It has been shown that a very good correlation exists between the charge density at the HB critical point and the strength of the interaction. ${ }^{8,12,13,23}$ For this purpose the charge densities at the bond critical points for all systems were located at the $\mathrm{HF} / 6-311++\mathrm{G}(d, p)$ level of theory. ${ }^{40}$
Total interaction energies for the various clusters are calculated as

$$
\Delta E=E(\text { cluster })-\Sigma E_{i},
$$

where the sum runs over all the monomers in the cluster. All interaction energies have been corrected for basis-set superposition error (BSSE) using the full counterpoise procedure. ${ }^{41}$ The negative of the interaction energy gives the dissociation energy $D_{e} . D_{0}$ would refer to the this quantity, after correction for zero-point energies. The enthalpy of formation of a given cluster is equal to $\Delta E$ with a $\Delta P V$ correction (assuming ideal gas behavior).

Finally, the cooperative effects themselves will be highlighted using several different indications. In order to quantitatively determine the cooperativity factor, the same method will be used as Mó et al. highlighted in previous work. ${ }^{12}$ It is defined as the relative shifts in the frequency of the donor $\mathrm{O}-\mathrm{H}$ stretching mode:

$$
A_{b}=\Delta \nu_{\mathrm{OH}} / \Delta \nu_{\mathrm{OH}^{\prime}},
$$

where the $\Delta \nu_{\mathrm{OH}^{\prime}}$ and $\Delta \nu_{\mathrm{OH}}$ represent the variation of the stretching frequency in the dimer and trimer with respect to the monomer, respectively.

It is important to point out that Mó et al. ${ }^{13}$ have carried out large basis set Hartree-Fock, MP2, and DFT/B3LYP calculations on the dimer and cylcic trimer of methanol. In particular, geometry optimizations and frequency calculations at the B3LYP/6-311+ $\mathrm{G}(d, p)$ level and interaction energies at the B3LYP/6-311++ $\mathrm{G}(3 d f, 2 p)$ for the $\left(\mathrm{CH}_{3} \mathrm{OH}\right)_{2}$ and $\left(\mathrm{CH}_{3} \mathrm{OH}\right)_{3}$ were performed by these authors.

\section{RESULTS AND DISCUSSION}

\section{A. Geometries}

The hydrogen bonded optimized structures for the different dimers and trimers studied in this work are shown in Figs. 1(A) $-1(\mathrm{D})$ and 2(A) $-2(\mathrm{D})$, respectively. The structural parameters for the methanol and trifluoromethanol monomers along with their corresponding changes upon complexation are summarized in Table I. Some relevant intermolecular parameters for the complexes are given in Table II.

\section{Intramolecular geometry}

The internal structure of each subunit is altered upon complexation. The extent of the structural change is an indication of the donor-acceptor behavior of the monomers in the complexes. This behavior may be traced to changes in the $\mathrm{O}-\mathrm{H}$ and $\mathrm{C}-\mathrm{O}$ bond lengths. An increase of the $\mathrm{O}-\mathrm{H}$ distance concomitant with a decrease in the $\mathrm{C}-\mathrm{O}$ distance would indicate a donor character whereas a lengthening of the $\mathrm{C}-\mathrm{O}$ bond would reflect an acceptor behavior.

Dimerization produces a noticeable increase in the length of the acceptor $\mathrm{C}-\mathrm{O}$ bond, while decreasing the donor $\mathrm{C}-\mathrm{O}$ bond. The magnitude of these changes for both donor and acceptor follows the order TM $>\mathrm{T}_{2}>\mathrm{M}_{2}>\mathrm{MT}$. This sequence indicates that the donor character of trifluoromethanol and the acceptor character of methanol are enhanced in the TM system relative to their corresponding dimers. This observation is supported also by the sequence of the donor 


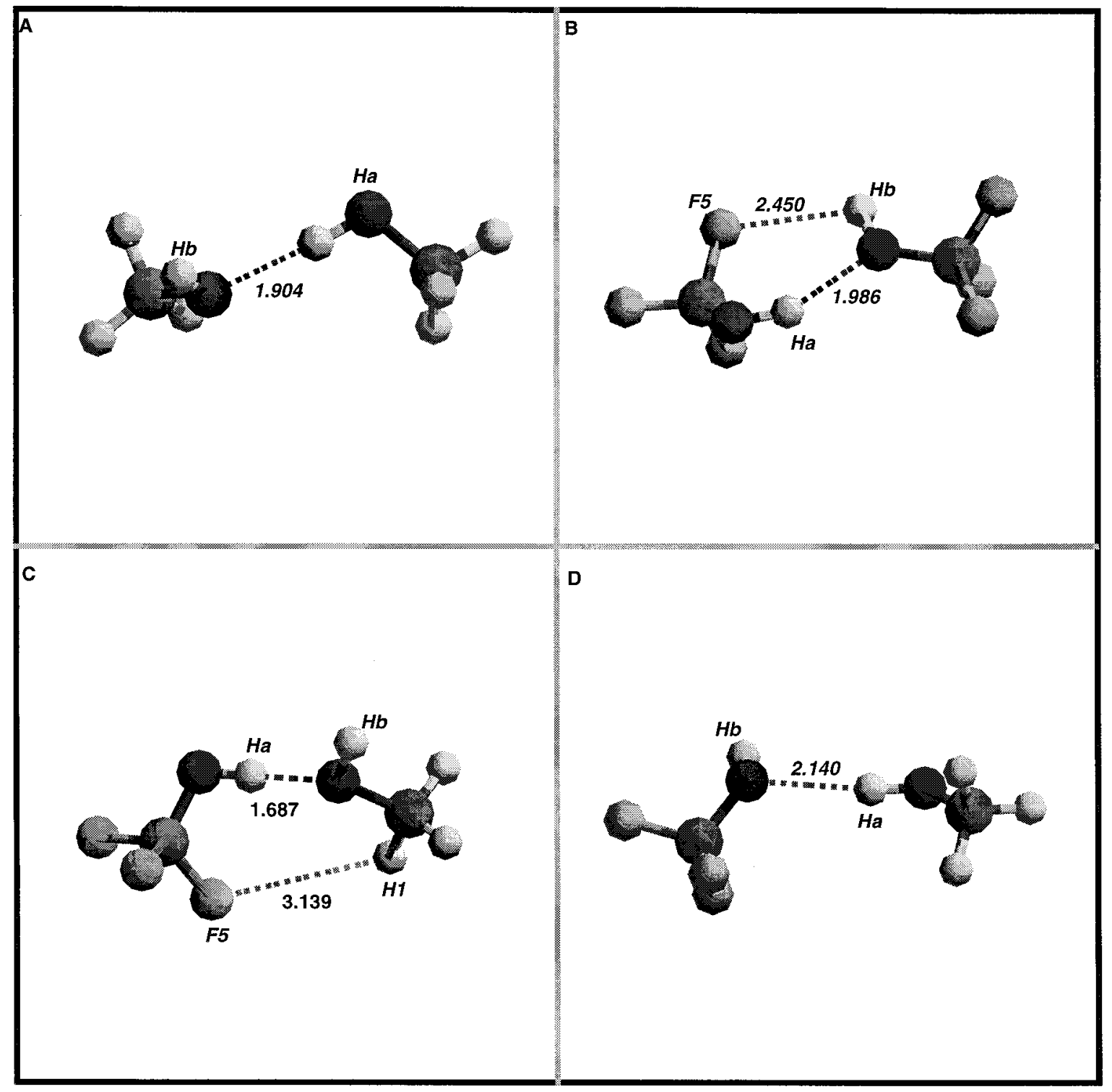

FIG. 1. B3LYP/6-311++ $\mathrm{G}(d, p)$ optimized structures of dimers and mixed dimers of methanol and trifluoromethanol: (A) methanol dimer; (B) trifluoromethanol dimer; (C) mixed dimer with trifluromethanol as donor; (D) mixed dimer with methanol as donor.

$\mathrm{O}-\mathrm{H}$ elongation, i.e., $\mathrm{TM}>\mathrm{M}_{2} \approx \mathrm{T}_{2}>\mathrm{MT}$. It is seen also that the poor acceptor behavior of $\mathrm{CF}_{3} \mathrm{OH}$ is more pronounced in the MT complex.

The donor $\mathrm{O}-\mathrm{H}$ bonds are significantly lengthened upon trimerization. In fact, cooperative effects may be quantified by these $\Delta r$ values. A comparison of $\Delta r$ between the methanol and trifluoromethanol trimers shows larger cooperativity for methanol (see Table V). Regarding the mixed trimers, we notice that the $\mathrm{O}-\mathrm{H}$ bond in the methanol moiety that is acting as $\mathrm{H}$ donor to $\mathrm{CF}_{3} \mathrm{OH}$ in both $\mathrm{T}_{2} \mathrm{M}$ and $\mathrm{M}_{2} \mathrm{~T}$ is slightly increased. This is consistent with the already mentioned poor acceptor nature of $\mathrm{CF}_{3} \mathrm{OH}$. However, the increase of the $\mathrm{O}-\mathrm{H}$ bond of the methanol that is $\mathrm{H}$ donor to methanol in $\mathrm{M}_{2} \mathrm{~T}$ is comparable to that in methanol trimer. With respect to the $\mathrm{CF}_{3} \mathrm{OH}$ unit, we see that the $\mathrm{O}-\mathrm{H}$ bond elongation is very large. In fact, the largest $\mathrm{O}-\mathrm{H}$ bond lengthening is found in the $\mathrm{M}_{2} \mathrm{~T}$ system $(0.041 \AA)$ followed by the $\mathrm{T}_{2} \mathrm{M}$ trimer $(0.038 \AA)$ where methanol is the acceptor molecule.
For the case in which the acceptor molecule is $\mathrm{CF}_{3} \mathrm{OH}$ $\left(\mathrm{T}_{2} \mathrm{M}\right)$, we also notice an increase of the $\mathrm{O}-\mathrm{H}$ bond which is comparable to that in the $\mathrm{T}_{3}$ system.

\section{Intermolecular structural parameters}

Among the key features of a hydrogen bond are the typically short $\mathrm{O} \ldots \mathrm{O}$ distance and the near linearity of the $\mathrm{O}-\mathrm{H} . . . \mathrm{O}$ arrangement. We find that in the dimers the $\mathrm{O} \ldots \mathrm{H}$ and the O...O intermolecular distances follow the order $\mathrm{TM}<\mathrm{M}_{2}<\mathrm{T}_{2}<\mathrm{MT}$, while for the $\mathrm{O}-\mathrm{H} . . . \mathrm{O}$ angle the order is $\mathrm{TM}>\mathrm{M}_{2}>\mathrm{MT}>\mathrm{T}_{2}$ (Table I). It is also apparent when looking at Fig. 1 that a long-range electrostatic interaction is taking place in TM between one of the fluorine atoms of the donor and the hydrogen atom trans to the $\mathrm{OH}$ group in the acceptor molecule.

It is worth mentioning that the dimer of $\mathrm{CF}_{3} \mathrm{OH}$ has some significant differences compared to methanol. The 


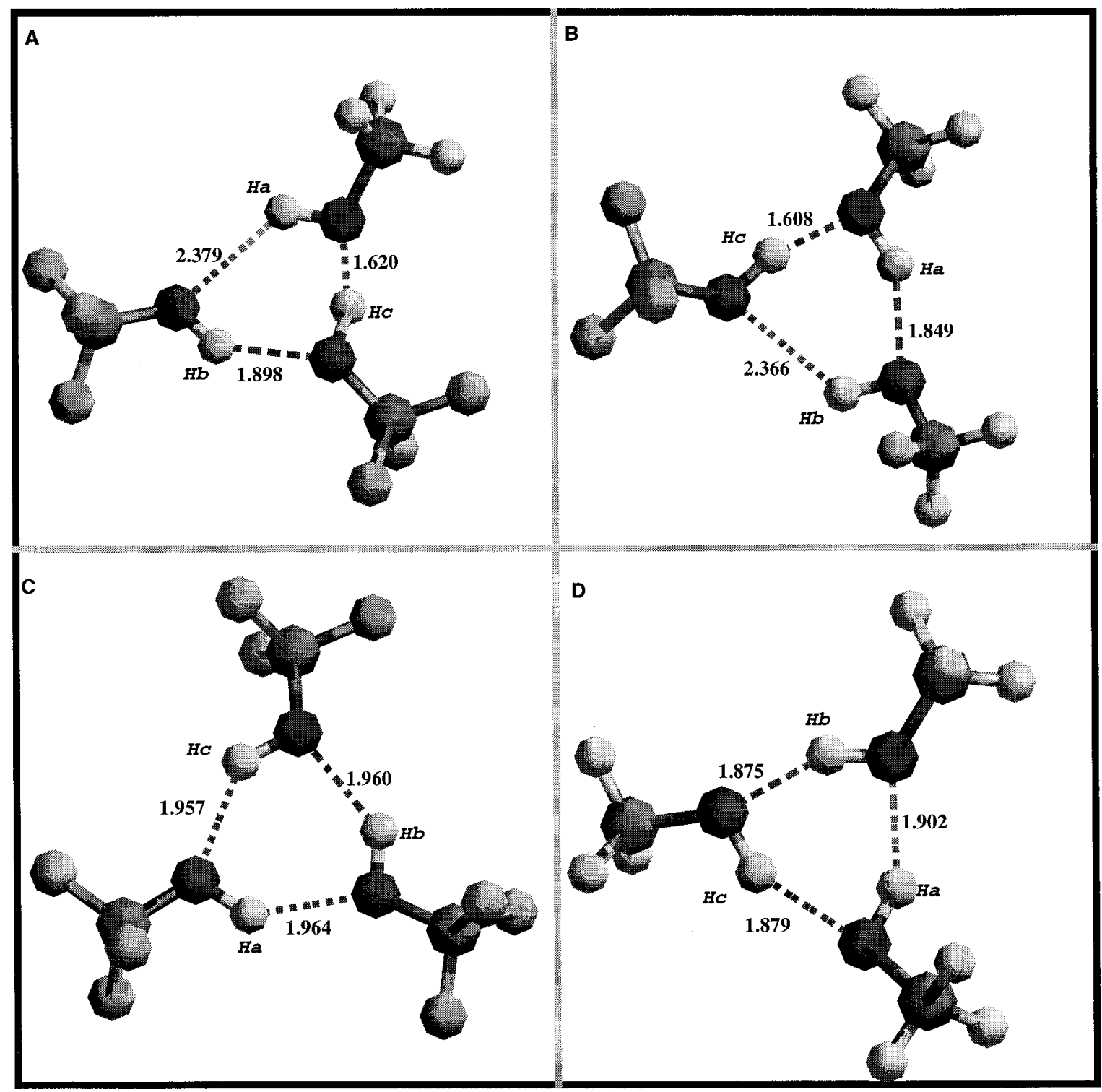

FIG. 2. B3LYP/6-311++ G(d,p) optimized structures of trimers and mixed trimers of methanol and trifluoromethanol: (A) mixed trimer with two molecules of trifluromethanol and one molecule of methanol; (B) mixed trimer with two molecules of methanol and one molecule of trifluoromethanol; (C) trimer of trifluromethanol; (D) trimer of methanol.

most striking feature is the deviation in linearity of the hydrogen bond (see Table I). Trifluoromethanol has a hydrogen-bond angle of $152^{\circ}$, while the hydrogen-bond angle of methanol is $176^{\circ}$. In addition, the hydrogen atom of the acceptor points preferably toward one of the fluorine atoms of the donor group. In fact, the distance between these two atoms is $2.450 \AA$ [Fig. 1(B)]. The corresponding $\mathrm{C}-\mathrm{F}$ distance in the donor is lengthened by $0.019 \AA$ and the acceptor $\mathrm{O}-\mathrm{H}$ distance is lengthened by $0.003 \AA$. These geometrical features suggest the existence of a secondary hydrogen bond between a fluorine atom in the donor monomer and the $\mathrm{OH}$ group of the acceptor. ${ }^{23}$ This secondary hydrogen bond helps to overcome the poor acceptor ability of $\mathrm{CF}_{3} \mathrm{OH}$.

Trimerization produces a noticeable reduction of the O...O distances. Similar results are found for the O...H distances, although in the $\mathrm{T}_{2} \mathrm{M}$ and $\mathrm{M}_{2} \mathrm{~T}$ clusters the $\mathrm{O} \ldots \mathrm{H}$ distance is actually lengthened for the $\mathrm{M}$ (donor)- $\mathrm{T}$ (acceptor) arrangement. Nevertheless the shortest $\mathrm{O} . . . \mathrm{H}$ and $\mathrm{O} \ldots \mathrm{O}$ dis- tances are found in the heterotrimers for the $\mathrm{T}$ (donor)$\mathrm{M}$ (acceptor) arrangement.

We observe that the three hydrogen bonds in $\mathrm{T}_{3}$ are practically equivalent as reflected by the similar bond lengths $(\approx 1.960 \AA)$ and the charge density at the corresponding critical points (see Table III). In contrast, the three hydrogen bonds in the other trimers are not strictly equivalent, but two are much stronger than the third one. Moreover, one of the hydrogen bonds in $\mathrm{T}_{2} \mathrm{M}$ and $\mathrm{M}_{2} \mathrm{~T}$ is significantly stronger than the other two. This is seen in the shorter bond length and a greater charge density at the corresponding critical points. A common feature for all trimers is the position of the methyl (trifluoromethyl) groups with respect to the $\mathrm{O}-\mathrm{O}-\mathrm{O}$ plane. We see that in all cases two groups are on the same side of the $\mathrm{O}-\mathrm{O}-\mathrm{O}$ plane, while the third one is found with an approximate trans conformation with respect to the other two. For methanol, this result is coherent with recent experimental studies. ${ }^{42}$ 
TABLE I. Structural parameters for the methanol and trifluoromethanol monomers and their corresponding changes upon complexation. ${ }^{\mathrm{a}}$

\begin{tabular}{lrrrrrr}
\hline \hline & \multicolumn{7}{c}{ Methanol unit } \\
& $\mathrm{C}-\mathrm{O}$ & $\mathrm{O}-\mathrm{H}$ & $\mathrm{C}-\mathrm{H}$ & \multicolumn{1}{c}{$\mathrm{C}-\mathrm{H}$} & $\mathrm{C}-\mathrm{H}$ & $\mathrm{H}-\mathrm{O}-\mathrm{C}$ \\
\hline $\mathrm{M}$ & 1.424 & 0.961 & 1.097 & 1.097 & 1.090 & 108.8 \\
$\mathrm{M}_{2}$ & -0.006 & 0.008 & 0.002 & 0.002 & 0.002 & 0.1 \\
& 0.008 & 0.001 & -0.002 & -0.002 & -0.001 & 0.5 \\
$\mathrm{M}_{3}$ & -0.001 & 0.014 & 0.000 & -0.001 & 0.001 & 1.3 \\
& 0.000 & 0.015 & -0.001 & -0.001 & 0.001 & 1.1 \\
& -0.001 & 0.015 & 0.000 & -0.001 & 0.001 & 1.3 \\
$\mathrm{TM}$ & 0.012 & 0.001 & -0.003 & -0.004 & -0.001 & 1.6 \\
$\mathrm{MT}$ & -0.001 & 0.001 & 0.000 & 0.000 & 0.000 & 0.1 \\
$\mathrm{~T}_{2} \mathrm{M}$ & 0.013 & 0.005 & -0.004 & -0.004 & -0.001 & 1.7 \\
$\mathrm{M}_{2} \mathrm{~T}$ & 0.007 & 0.016 & -0.002 & -0.003 & 0.000 & 2.1 \\
& 0.007 & 0.005 & -0.002 & -0.003 & 0.000 & 0.9 \\
& & & & & & \\
& $\mathrm{C}-\mathrm{O}$ & $\mathrm{O}-\mathrm{H}$ & $\mathrm{C}-\mathrm{F}$ & $\mathrm{C}-\mathrm{F}$ & $\mathrm{C}-\mathrm{F}$ & $\mathrm{H}-\mathrm{O}-\mathrm{C}$ \\
\hline $\mathrm{T}$ & 1.346 & 0.966 & 1.354 & 1.354 & 1.331 & 109.5 \\
$\mathrm{~T}_{2}$ & -0.011 & 0.007 & 0.019 & 0.000 & -0.001 & -0.4 \\
& 0.011 & 0.003 & -0.008 & -0.008 & -0.001 & 1.3 \\
$\mathrm{~T}_{3}$ & 0.006 & 0.010 & -0.005 & -0.008 & 0.002 & 2.4 \\
& 0.006 & 0.010 & -0.005 & -0.007 & 0.002 & 2.3 \\
& 0.006 & 0.010 & -0.006 & -0.007 & 0.002 & 2.6 \\
$\mathrm{TM}$ & -0.020 & 0.024 & 0.012 & 0.006 & 0.008 & 1.2 \\
$\mathrm{MT}$ & 0.006 & 0.001 & -0.005 & -0.005 & 0.000 & 1.4 \\
$\mathrm{~T}_{2} \mathrm{M}$ & -0.008 & 0.038 & 0.000 & 0.000 & 0.007 & -0.1 \\
& -0.004 & 0.012 & 0.000 & -0.003 & 0.006 & -0.8 \\
$\mathrm{M}_{2} \mathrm{~T}$ & -0.019 & 0.041 & 0.008 & 0.004 & 0.012 & 0.3 \\
\hline \hline
\end{tabular}

${ }^{a}$ In $M_{2}$ and $T_{2}$ the first row is for donor, second for acceptor; in $\mathrm{M}_{2} \mathrm{~T}$ and $\mathrm{T}_{2} \mathrm{M}$ the first row is for donor to methanol, the second for donor to trifluoromethanol; distance in $\AA$, angles in degrees.

A structure where the three methyl groups lie in the $\mathrm{O}-\mathrm{O}-\mathrm{O}$ plane in the methanol trimer was found to be a saddle point of third order by Mó et al. ${ }^{13}$ They found this structure to be $1.46 \mathrm{kcal} / \mathrm{mol}$ less stable than the global

TABLE II. Relevant intermolecular parameters. Distance is in $\AA$, angles in degrees. ${ }^{\mathrm{a}}$

\begin{tabular}{lcccc}
\hline \hline & $\mathrm{M}_{2}$ & $\mathrm{~T}_{2}$ & $\mathrm{TM}$ & $\mathrm{MT}$ \\
\hline$r_{\mathrm{O}--\mathrm{H}}$ & 1.904 & 1.986 & 1.687 & 2.140 \\
$r_{\mathrm{O}-\mathrm{O}}$ & 2.873 & 2.881 & 2.677 & 3.074 \\
$A_{\mathrm{O}-\mathrm{HO}}$ & 176.2 & 151.7 & 179.6 & 163.0 \\
& & & & \\
& $\mathrm{M}_{3}$ & $\mathrm{~T}_{3}$ & $\mathrm{~T}_{2} \mathrm{M}$ & $\mathrm{M}_{2} \mathrm{~T}$ \\
\hline$r_{\mathrm{Ob}-\mathrm{Ha}}$ & 1.902 & 1.965 & 2.379 & 1.849 \\
$r_{\mathrm{Oc}-\mathrm{Hb}}$ & 1.875 & 1.959 & 1.898 & 2.366 \\
$r_{\mathrm{Oa}-\mathrm{Hc}}$ & 1.879 & 1.958 & 1.619 & 1.608 \\
$r_{\mathrm{Oa}-\mathrm{Ob}}$ & 2.779 & 2.759 & 3.012 & 2.733 \\
$r_{\mathrm{Ob}--\mathrm{Oc}}$ & 2.769 & 2.760 & 2.737 & 3.070 \\
$r_{\mathrm{Oc}-\mathrm{Oa}}$ & 2.769 & 2.763 & 2.594 & 2.588 \\
$A_{\mathrm{O}-\mathrm{HaO}}$ & 148.2 & 136.9 & 122.6 & 149.1 \\
$A_{\mathrm{O}-\mathrm{HbO}}$ & 150.9 & 137.6 & 142.2 & 129.3 \\
$A_{\mathrm{O}-\mathrm{HcO}}$ & 150.3 & 138.2 & 162.4 & 163.0 \\
$A_{\mathrm{COa}-\mathrm{Hc}}$ & 133.3 & 140.6 & 126.1 & 124.1 \\
$A_{\mathrm{COb}-\mathrm{Ha}}$ & 136.2 & 143.3 & 150.1 & 131.5 \\
$A_{\mathrm{COc}-\mathrm{Hb}}$ & 128.8 & 139.7 & 136.3 & 134.8 \\
$\tau_{\mathrm{CaOCObOa}}$ & 14.0 & 6.0 & 13.8 & 17.8 \\
$\tau_{\mathrm{CcObOaOc}}$ & -16.5 & -7.4 & -12.5 & -14.2 \\
$\tau_{\mathrm{CbOaOcOb}}$ & 13.5 & 3.8 & 5.0 & -12.7 \\
\hline \hline
\end{tabular}

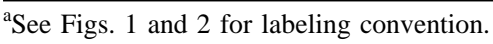

TABLE III. Charge densities (in e $\left.\mathrm{au}^{-3}\right)$ at the bond critical points $\left(\rho_{c}\right)$ and calculated dipole moment $(\mu)$ and dipole moment enhancements $(\Delta \mu)$; dipole units in debyes. ${ }^{\text {a }}$

\begin{tabular}{lccccc}
\hline \hline & $\rho_{\mathrm{C}-\mathrm{O}}$ & $\rho_{\mathrm{O}-\mathrm{H}}$ & $\rho_{\mathrm{HB}}$ & $\mu$ & $\Delta \mu$ \\
\hline $\mathrm{M}$ & 0.249 & 0.372 & & 1.69 & \\
$\mathrm{M}_{2}$ & 0.255 & 0.359 & 0.025 & 3.01 & 0.82 \\
& 0.240 & 0.370 & & & \\
$\mathrm{M}_{3}$ & 0.251 & 0.350 & 0.029 & 0.75 & -0.03 \\
& 0.250 & 0.350 & 0.030 & & \\
& 0.251 & 0.349 & 0.027 & & \\
$\mathrm{~T}$ & 0.329 & 0.360 & & 2.00 & \\
$\mathrm{~T}_{2}$ & 0.339 & 0.349 & 0.019 & 1.70 & 0.27 \\
& 0.317 & 0.354 & & & \\
$\mathrm{~T}_{3}$ & 0.321 & 0.343 & 0.020 & 0.05 & 0.00 \\
& 0.321 & 0.343 & 0.020 & & \\
& 0.321 & 0.343 & 0.020 & & \\
$\mathrm{TM}$ & 0.344 & 0.325 & 0.041 & 5.22 & 1.36 \\
& 0.234 & 0.368 & & & \\
$\mathrm{MT}$ & 0.249 & 0.369 & 0.014 & 1.00 & 0.11 \\
& 0.323 & 0.357 & & & \\
$\mathrm{~T}_{2} \mathrm{M}$ & 0.332 & 0.307 & 0.050 & 4.16 & 1.31 \\
& 0.330 & 0.341 & 0.024 & & \\
$\mathrm{M}_{2} \mathrm{~T}$ & 0.233 & 0.363 & 0.009 & & \\
& 0.343 & 0.304 & 0.052 & 4.13 & 1.38 \\
& 0.239 & 0.347 & 0.029 & & \\
\hline \hline
\end{tabular}

${ }^{\mathrm{a}}$ In the dimers the results are given in the donor-acceptor order; in $\mathrm{T}_{2} \mathrm{M}$ they are given in the TM, TT, MT order, while in $\mathrm{M}_{2} \mathrm{~T}$ the results are given in the TM, MM, MT sequence; densities calculated at the $\mathrm{HF} / 6-311++\mathrm{G}(d, p)$; dipole moments calculated at the B3LYP/6-311++G(3d,2p).

minimum. A similar result was found for the trimer of trifluoromethanol by Doering et al. ${ }^{23}$ at the $\mathrm{HF} / 6-311++\mathrm{G}(2 d, 2 p)$ level. We also investigated the existence of these symmetric trimers. Our results for the methanol trimer are essentially the same as those found by Mó et al. ${ }^{13}$ Regarding the symmetric trifluoromethanol trimer, we found this structure, using our highest basis set, to be only $0.19 \mathrm{kcal} / \mathrm{mol}$ less stable than the nonplanar $\mathrm{T}_{3}$ system. This result clearly indicates that the potential energy surface associated with the out-of-plane displacements of the $\mathrm{CF}_{3}$ groups of a trifluoromethanol trimer is very flat, even flatter than that of the corresponding $\mathrm{CH}_{3}$ groups in the methanol trimer.

\section{B. Charge densities}

The observations made on the structural features of the complexes are mirrored in the charge densities shown in Table III. Upon dimerization, $\rho_{c}$ for $\mathrm{C}-\mathrm{O}$ increases for the donor and decreases for the acceptor. An increase in $\rho_{c}$ signals a stronger bond, and thus a shorter bond length. This effect is more pronounced in TM and negligible in MT. Upon trimerization, the charge density for the $\mathrm{C}-\mathrm{O}$ bond in $\mathrm{M}_{3}$ and $\mathrm{T}_{3}$ moves closer to that of the monomer. However, the charge densities for the $\mathrm{C}-\mathrm{O}$ bond of the methanol moiety in $\mathrm{T}_{2} \mathrm{M}$ and $\mathrm{M}_{2} \mathrm{~T}$ are even smaller than those of the corresponding donor in the dimers and heterodimers.

Charge densities as calculated at the bond critical points are an indication of cooperative effects. One important trend to look for is the decrease of $\rho_{c}$ for the donor $\mathrm{O}-\mathrm{H}$ bond 
upon dimerization and trimerization. Because charge density is an indication of bond strength, this decrease implies that the $\mathrm{O}-\mathrm{H}$ bond is being slightly weakened. The weakening of this bond is due to the favorable hydrogen bonding. Cooperativity lowers the charge density even more, which is why $\rho_{c}$ is lower in the trimer than in the dimer for the $\mathrm{O}-\mathrm{H}$ bond. Another indication of cooperativity is seen in the strengthening of the hydrogen bond in the trimer as opposed to the dimer. This is observed as an increase in $\rho_{c}$ at the hydrogen bond upon trimerization. These cooperative effects are more significant in the heterotrimers.

\section{Dipole moment enhancement}

The formation of a first hydrogen bond in a dimer will distort the charge distribution of each monomer. This polarization leads to a dipole moment in the dimer that is larger than the vector sum of the individual monomers. This enhanced dipole moment is an expression of the cooperative nature of hydrogen bonds. To investigate this property, we have evaluated the variation of the dipole moment upon dimerization and trimerization as the difference between the dipole moment of the corresponding cluster and that obtained by vector sum of the individual dipole moments. To calculate the dipole moment of each subunit, the complete set of basis functions of the clusters was used and the geometry of each monomer was frozen in that of the optimized cluster. The results so obtained are listed in Table III. We see that dimerization is accompanied by a significant enhancement of the dipole moment. The magnitude of this enhancement parallels the strength of the hydrogen bond in the clusters, $T M>M_{2}>T_{2}>M T$. For the $M_{3}$ and $T_{3}$ clusters there is no dipole enhancement, due to the fact that these trimers have a cyclic structure. However, the $T_{2} M$ and $M_{2} T$ systems show a significant dipole enlargement $\left(\mathrm{M}_{2} \mathrm{~T}>\mathrm{T}_{2} \mathrm{M}\right)$ because these trimers are formed with different monomers and the cyclic structure does not necessarily counteract the possible enhancements on each molecule.

\section{Vibrational frequencies}

The optimized geometries of the clusters were used to calculate the normal mode frequencies within the harmonic oscillator approximation. The results are listed in Table IV. The shifts of some vibrational modes upon complexation are displayed in Table V. As one would expect, there is a sizable redshift in the stretching mode of the donor $\mathrm{O}-\mathrm{H}$ bond upon formation of a dimer. The calculated redshifts for $\mathrm{M}_{2}$ and $\mathrm{T}_{2}$ are 158 and $124 \mathrm{~cm}^{-1}$, respectively, while those for TM and MT are 478 and $22 \mathrm{~cm}^{-1}$, respectively. It can be seen that the acceptor $\mathrm{O}-\mathrm{H}$ stretching frequency in $\mathrm{T}_{2}$ also undergoes a notable redshift of $35 \mathrm{~cm}^{-1}$. This is a result of the secondary hydrogen bond found in this dimer.

Another mode of vibration that is affected is the $\mathrm{C}-\mathrm{O}$ stretching mode. Table $\mathrm{V}$ shows that upon dimerization the donor $\mathrm{C}-\mathrm{O}$ frequencies $\mathrm{M}_{2}$ and $\mathrm{T}_{2}$ are blueshifted by 21 and $29 \mathrm{~cm}^{-1}$, respectively. Similarly, the donor C-O stretching mode in TM is blueshifted by $47 \mathrm{~cm}^{-1}$, this is $18 \mathrm{~cm}^{-1}$ more than in $\mathrm{T}_{2}$. The donor $\mathrm{C}-\mathrm{O}$ mode in MT is blueshifted by 7 $\mathrm{cm}^{-1}$, this is $14 \mathrm{~cm}^{-1}$ less than in $\mathrm{M}_{2}$.
Dimerization also has strong effects upon the donor $\mathrm{O}-\mathrm{H}$ torsion and bending modes; both modes are blueshifted by significant amounts. The torsion frequencies of the donor are blueshifted by 403 and $288 \mathrm{~cm}^{-1}$ for $\mathrm{M}_{2}$ and $\mathrm{T}_{2}$, respectively. The corresponding blue shift in TM is $581 \mathrm{~cm}^{-1}$, which is significantly larger (more than $290 \mathrm{~cm}^{-1}$ ) than that in $\mathrm{T}_{2}$; however, the calculated blueshift of the torsion mode in MT is $281 \mathrm{~cm}^{-1}$ less than that in $\mathrm{M}_{2}$. The donor $\mathrm{O}-\mathrm{H}$ bending modes are shifted to higher frequencies by 62 and $40 \mathrm{~cm}^{-1}$ for $\mathrm{M}_{2}$ and $\mathrm{T}_{2}$, respectively. The corresponding frequency shifts in TM and MT are 68 and $36 \mathrm{~cm}^{-1}$. In all cases, the shifts of the $\mathrm{O}-\mathrm{H}$ group not involved in the hydrogen bond are considerably smaller.

Many of the same qualitative trends seen upon dimerization are also noted upon trimerization. The $\mathrm{O}-\mathrm{H}$ stretching frequencies are affected by trimerization even more than dimerization. The redshift ranges from 233 to $299 \mathrm{~cm}^{-1}$ for $\mathrm{M}_{3}$ and from 160 to $200 \mathrm{~cm}^{-1}$ for $\mathrm{T}_{3}$. This increase in the redshift of the donor $\mathrm{O}-\mathrm{H}$ stretch is one method of determining that cooperative effects are present. In fact, this frequency variation is actually used to quantify the cooperativity factor as seen in Eq. (2). The effect of trimerization also increases the shifts seen in the $\mathrm{C}-\mathrm{O}$ stretching frequencies. Two of the $\mathrm{C}-\mathrm{O}$ stretches in $\mathrm{T}_{3}$ are redshifted by $36 \mathrm{~cm}^{-1}$, while the other is blueshifted by $48 \mathrm{~cm}^{-1}$. All three $\mathrm{C}-\mathrm{O}$ stretches in $\mathrm{M}_{3}$ are shifted to the blue.

It is worth mentioning that, in general, the shifts of the $\mathrm{O}-\mathrm{H}$ stretching and torsion frequencies in the mixed trimers are considerably larger than in the trimers and heterodimers. For example, the $\mathrm{O}-\mathrm{H}$ stretch frequency shift of the $\mathrm{CF}_{3} \mathrm{OH}$ unit that acts as a $\mathrm{H}$ donor to the methanol unit in the $\mathrm{T}_{2} \mathrm{M}$ cluster is $250 \mathrm{~cm}^{-1}$ larger than in TM and more than 3 times larger than in $\mathrm{T}_{3}$.

\section{E. Energetics and cooperativity}

The electronic interaction energies (counterpoise corrected) for the B3LYP/6-311++ $\mathrm{G}(d, p)$ optimized dimers and mixed dimers of methanol and trifluoromethanol were computed with the $6-311++\mathrm{G}(d, p)$, 6-311++ $\mathrm{G}(2 d$, $2 p)$, and $6-311++\mathrm{G}(3 d, 2 p)$ basis sets at the HF, MP2, and B3LYP levels. The results are shown in Table VI. Also shown in Table VI is the correlation contribution from the MP2 and the B3LYP models. The interaction energies for the optimized trimers and mixed trimers were obtained with the $6-311++\mathrm{G}(d, p)$ at the MP2 level. The dissociation energies and dissociation enthalpies for the various clusters at 0 $\mathrm{K}$ and at room temperature are given in Table VII. There is good agreement between the calculated dissociation enthalpies and previous theoretical ${ }^{13}$ and experimental ${ }^{43,44}$ values.

From Table VI, we observe that the MP2 interaction energies are consistently improved as the size of the basis set is increased. The HF interaction energies calculated with the $6-311++\mathrm{G}(2 d, 2 p)$ basis set are very similar to those obtained with the $6-311++\mathrm{G}(3 d, 2 p)$ basis set although they are considerably smaller than those obtained with the $6-311++\mathrm{G}(d, p)$ basis set. This is also the case for the B3LYP model.

We can see also that in each system the correlation contribution from the MP2 model is significantly improved with 
TABLE IV. Harmonic vibrational frequencies $\left(\mathrm{cm}^{-1}\right)$ obtained at the B3LYP/6-311++ $\mathrm{G}(d, p)$ level. ${ }^{\mathrm{a}}$

\begin{tabular}{|c|c|c|c|c|c|c|c|c|c|c|c|c|}
\hline \multirow[b]{2}{*}{ M } & \multirow{2}{*}{$\frac{\tau_{\mathrm{OH}}}{298}$} & \multirow{2}{*}{$\frac{s_{\mathrm{CO}}}{1042}$} & \multirow{2}{*}{$\frac{b_{\mathrm{OH}}}{1356}$} & \multirow{2}{*}{$\frac{s_{\mathrm{OH}}}{3846}$} & \multicolumn{8}{|c|}{ Other normal modes } \\
\hline & & & & & 3112 & 3036 & 2989 & 1505 & 1494 & 1480 & 1168 & 1070 \\
\hline \multirow[t]{3}{*}{$\mathrm{M}_{2}$} & 701 & 1063 & 1418 & 3688 & 3092 & 3014 & 2973 & 1508 & 1494 & 1480 & 1169 & 1113 \\
\hline & 341 & 1035 & 1360 & 3843 & 3128 & 3070 & 3011 & 1505 & 1497 & 1479 & 1170 & 1075 \\
\hline & & & & & 188 & 123 & 106 & 52 & 45 & 24 & & \\
\hline \multirow[t]{5}{*}{$\mathrm{M}_{3}$} & 645 & 1052 & 1408 & 3547 & 3104 & 3044 & 2994 & 1510 & 1496 & 1477 & 1172 & 1115 \\
\hline & 742 & 1054 & 1418 & 3600 & 3106 & 3046 & 2996 & 1510 & 1497 & 1477 & 1172 & 1124 \\
\hline & 815 & 1068 & 1465 & 3613 & 3106 & 3050 & 2999 & 1513 & 1497 & 1486 & 1173 & 1157 \\
\hline & & & & & 210 & 208 & 188 & 176 & 118 & 116 & 107 & 91 \\
\hline & & & & & 83 & 62 & 42 & 41 & & & & \\
\hline $\mathrm{T}$ & 242 & 1266 & 1392 & 3812 & 1131 & 1086 & 884 & 623 & 609 & 593 & 446 & 435 \\
\hline \multirow{3}{*}{$\mathrm{T}_{2}$} & 530 & 1295 & 1432 & 3688 & 1131 & 1101 & 877 & 621 & 608 & 597 & 399 & 433 \\
\hline & 321 & 1248 & 1386 & 3777 & 1162 & 1068 & 890 & 632 & 613 & 605 & 458 & 445 \\
\hline & & & & & 123 & 80 & 48 & 33 & 21 & 17 & & \\
\hline \multirow[t]{5}{*}{$\mathrm{T}_{3}$} & 499 & 1230 & 1403 & 3612 & 1164 & 1106 & 890 & 631 & 611 & 603 & 388 & 445 \\
\hline & 518 & 1231 & 1407 & 3648 & 1154 & 1108 & 890 & 632 & 612 & 604 & 397 & 445 \\
\hline & 592 & 1314 & 1409 & 3652 & 1152 & 1132 & 896 & 643 & 624 & 630 & 410 & 452 \\
\hline & & & & & 122 & 121 & 117 & 98 & 41 & 38 & 33 & 30 \\
\hline & & & & & 29 & 24 & 16 & 12 & & & & \\
\hline \multicolumn{13}{|l|}{ TM } \\
\hline $\mathrm{T}$ & 826 & 1313 & 1460 & 3334 & 1125 & 1095 & 878 & 623 & 611 & 607 & 446 & 423 \\
\hline \multirow[t]{2}{*}{ M } & 320 & 1030 & 1359 & 3850 & 3140 & 3090 & 3025 & 1507 & 1498 & 1482 & 1171 & 1077 \\
\hline & & & & & 213 & 120 & 72 & 53 & 35 & 20 & & \\
\hline \multicolumn{13}{|l|}{ MT } \\
\hline $\mathrm{M}$ & 420 & 1049 & 1392 & 3824 & 3108 & 3034 & 2988 & 1506 & 1494 & 1480 & 1168 & 1080 \\
\hline \multirow[t]{2}{*}{$\mathrm{T}$} & 292 & 1254 & 1380 & 3796 & 1149 & 1106 & 887 & 627 & 612 & 596 & 463 & 443 \\
\hline & & & & & 104 & 89 & 59 & 30 & 10 & -15 & & \\
\hline \multicolumn{13}{|l|}{$\mathrm{T}_{2} \mathrm{M}$} \\
\hline M & 478 & 1030 & 1375 & 3795 & 3139 & 3095 & 3026 & 1507 & 1498 & 1492 & 1174 & 1092 \\
\hline $\mathrm{T}$ & 915 & 1245 & 1464 & 3084 & 1156 & 1130 & 888 & 632 & 613 & 607 & 447 & 429 \\
\hline \multirow[t]{3}{*}{$\mathrm{T}$} & 650 & 1311 & 1417 & 3589 & 1139 & 1107 & 884 & 627 & 611 & 580 & 445 & 410 \\
\hline & & & & & 237 & 146 & 124 & 95 & 89 & 69 & 42 & 39 \\
\hline & & & & & 35 & 25 & 24 & 20 & & & & \\
\hline \multicolumn{13}{|l|}{$\mathrm{M}_{2} \mathrm{~T}$} \\
\hline M & 762 & 1048 & 1410 & 3571 & 3125 & 3078 & 3029 & 1510 & 1499 & 1490 & 1179 & 1092 \\
\hline M & 481 & 1039 & 1385 & 3786 & 3124 & 3074 & 3014 & 1509 & 1497 & 1478 & 1172 & 1110 \\
\hline \multirow[t]{3}{*}{$\mathrm{T}$} & 960 & 1303 & 1470 & 3001 & 1159 & 1119 & 879 & 626 & 614 & 610 & 447 & 427 \\
\hline & & & & & 244 & 215 & 147 & 116 & 110 & 98 & 83 & 66 \\
\hline & & & & & 47 & 42 & 28 & 18 & & & & \\
\hline
\end{tabular}

${ }^{\mathrm{a}} \tau, s$, and $b$ stand for torsional, stretching, and bending modes, respectively.

the basis set size. For instance, the correlation contribution for the TM system using the largest basis set is 2.5 times that obtained with the smallest basis set. However, the correlation contribution from the B3LYP model does not change much with the size of the basis set. The B3LYP model underestimates the correlation contribution in all systems. This is more pronounced in the $\mathrm{T}_{2}$ and MT systems where the correlation contribution is underestimated by more than a factor of 2. These results are consistent with the results of Novoa and Sosa $^{36}$ and support their conclusion that the DFT model is not a reliable method to study the energetics of hydrogenbonded systems.

The strength of the hydrogen-bonding interaction, in the various dimers and mixed dimers, follows the order $\mathrm{TM}>\mathrm{M}_{2}>\mathrm{T}_{2}>\mathrm{MT}$. This order is the same at all levels of theory. It is worth mentioning that the difference in interaction between the different complexes can be found already at the self-consistent field (SCF)-HF level, since its origin is in the electrostatic and induction interaction, which are well described already at the SCF-HF level, and consequently also in the DFT-B3LYP model.

From Table VIII, we see that the strength of the hydrogen-bonding interaction, in the various trimers and mixed trimers, follows the order $\mathrm{M}_{2} \mathrm{~T}>\mathrm{T}_{2} \mathrm{M}>\mathrm{M}_{3}>\mathrm{T}_{3}$. We observe also that except for $\mathrm{T}_{3}$, the trimerization enthalpies are predicted to be more than that obtained from the constituent dimers. This fact indicates that cooperative effects as seen from considerations of the energetics must be important in the $\mathrm{M}_{3}, \mathrm{~T}_{2} \mathrm{M}$, and $\mathrm{M}_{2} \mathrm{~T}$ complexes. For instance, the dissociation enthalpy of $\mathrm{M}_{2} \mathrm{~T}$ at $0 \mathrm{~K}$ exceeds by $1.94 \mathrm{kcal} / \mathrm{mol}$ the sum of the corresponding enthalpies of the TM, MT, and $\mathrm{M}_{2}$ dimers at the MP2/6-311++G( $(d, p)$. The cooperativity increases further at room temperature. The presence of a secondary hydrogen bond in the trifluoromethanol dimer is mainly responsible for the negative cooperativity observed in $\mathrm{T}_{3}$.

A different way of measuring cooperative effects is through the computation of the three-body interaction en- 
TABLE V. Cooperativity parameters. O--O distances, $R_{00}(\AA)$; elongation of the O-H bonds, $\Delta r(\AA)$; shifts of the $\mathrm{C}-\mathrm{O}$ stretching and of the $\mathrm{O}-\mathrm{H}$ stretching, bending, and torsional modes, $\Delta \nu\left(\mathrm{cm}^{-1}\right)$; and cooperativity factors, $A_{b}$.

\begin{tabular}{lccccrrr}
\hline \hline & $R_{00}$ & $\Delta r$ & $\Delta \nu\left(\mathrm{OH}_{s}\right)$ & $\Delta \nu\left(\mathrm{OH}_{\tau}\right)$ & $\Delta \nu\left(\mathrm{OH}_{b}\right)$ & $\Delta \nu\left(\mathrm{CO}_{s}\right)$ & $A_{b}$ \\
\hline $\mathrm{M}_{2}$ & 2.873 & 0.008 & -158 & 403 & 62 & 21 & \\
& & & -3 & 43 & 4 & -7 & \\
$\mathrm{M}_{3}$ & 2.769 & 0.014 & -299 & 517 & 109 & 16 & 1.9 \\
& 2.769 & 0.015 & -246 & 444 & 62 & 12 & 1.6 \\
& 2.779 & 0.015 & -233 & 347 & 52 & 10 & 1.5 \\
$\mathrm{~T}_{2}$ & 2.881 & 0.007 & -124 & 288 & 40 & 29 & \\
& & & -35 & 79 & -6 & -18 & \\
$\mathrm{~T}_{3}$ & 2.759 & 0.010 & -200 & 350 & 17 & 48 & 1.6 \\
& 2.760 & 0.010 & -164 & 276 & 15 & -36 & 1.3 \\
& 2.763 & 0.010 & -160 & 257 & 11 & -35 & 1.3 \\
$\mathrm{TM}$ & 2.677 & 0.024 & -478 & 581 & 68 & 47 & \\
& & & 4 & 22 & 3 & -12 & \\
$\mathrm{MT}$ & 3.074 & 0.001 & -22 & 122 & 36 & -12 & \\
& & & -16 & 50 & -12 & -12 & 2.3 \\
$\mathrm{~T}_{2} \mathrm{M}^{\mathrm{a}}$ & 3.012 & 0.005 & -51 & 180 & 19 & -21 & 1.5 \\
& 2.595 & 0.038 & -728 & 673 & 72 & 45 & 1.8 \\
& 2.737 & 0.012 & -223 & 408 & 25 & 6 & 1.7 \\
$\mathrm{M}_{2} \mathrm{~T}^{\mathrm{b}}$ & 2.733 & 0.016 & -275 & 464 & 44 & -3 & 2.7 \\
& 3.070 & 0.005 & -60 & 183 & 29 & 47 & 1.7 \\
\hline \hline
\end{tabular}

${ }^{\mathrm{a}}$ Data given in the MT, TM, TT sequence.

${ }^{\mathrm{b}}$ Data given in the MM, MT, TM sequence.

ergy, $\Delta E_{3}$. This quantity is defined as the difference between the total interaction energy of the trimer, and the sum of the interaction energies of the different dimers we can find within the trimer, all computed as $\Delta E_{\text {elec }}$. It is important to note that the three-body term is evaluated with the geometry of all species frozen in that of the optimized trimer, so the effects of any geometry distortion are present here too.

The resulting quantities for the various trimers are reported in Table VII. It is immediately clear that the formation of the trimers implies a significant net energy gain in all cases, including $T_{3}$. We found that the average interaction energy of the different dimers of trifluoromethanol within the trimer is $3.36 \mathrm{kcal} / \mathrm{mol}$. This gives an upper estimate of 1.40 $\mathrm{kcal} / \mathrm{mol}$ for the secondary hydrogen bond present in the fully optimized dimer.

\section{F. Basis set superposition error}

The basis set superposition error (BSSE) on the interaction energies has been estimated for all the optimized com-

TABLE VI. Electronic interaction energies $(\mathrm{kcal} / \mathrm{mol})$ for the dimers and heterodimers at the HF, MP2, and B3LYP levels and different basis sets.

\begin{tabular}{|c|c|c|c|c|c|c|c|c|}
\hline & \multicolumn{3}{|c|}{$\mathrm{M}_{2}$} & \multicolumn{3}{|c|}{$\mathrm{T}_{2}$} & & \\
\hline & $\mathrm{HF}$ & MP2 & B3LYP & $\mathrm{HF}$ & MP2 & B3LYP & & \\
\hline \multirow{5}{*}{$\begin{array}{l}6-311++\mathrm{G}(d, p) \\
6-311++\mathrm{G}(2 d, 2 p) \\
6-311++\mathrm{G}(3 d, 2 p)\end{array}$} & -4.19 & -5.04 & -5.16 & -3.77 & -4.76 & -4.50 & & \\
\hline & -3.74 & -5.20 & -4.74 & -3.18 & -4.83 & -3.96 & & \\
\hline & -3.77 & -5.34 & -4.78 & -3.21 & -5.04 & -4.04 & & \\
\hline & \multicolumn{3}{|c|}{$\mathrm{TM}$} & \multicolumn{3}{|c|}{ MT } & & \\
\hline & $\mathrm{HF}$ & MP2 & B3LYP & $\mathrm{HF}$ & MP2 & B3LYP & & \\
\hline $6-311++\mathrm{G}(d, p)$ & -9.76 & -10.45 & -10.77 & -1.32 & -2.08 & -1.82 & & \\
\hline $6-311++\mathrm{G}(2 d, 2 p)$ & -8.90 & -10.46 & -10.01 & -1.04 & -2.16 & -1.61 & & \\
\hline \multirow[t]{4}{*}{$6-311++\mathrm{G}(3 d, 2 p)$} & -8.92 & -10.64 & -10.01 & -1.06 & -2.27 & -1.60 & & \\
\hline & \multicolumn{8}{|c|}{ Correlation contribution } \\
\hline & \multicolumn{2}{|c|}{$\mathrm{M}_{2}$} & \multicolumn{2}{|c|}{$\mathrm{T}_{2}$} & \multicolumn{2}{|c|}{$\mathrm{TM}$} & \multicolumn{2}{|c|}{ MT } \\
\hline & MP2 & B3LYP & MP2 & B3LYP & MP2 & B3LYP & MP2 & B3LYP \\
\hline $6-311++\mathrm{G}(d, p)$ & -0.85 & -1.03 & -1.01 & -0.73 & -0.69 & -1.01 & -0.76 & -0.50 \\
\hline $6-311++\mathrm{G}(2 d, 2 p)$ & -1.46 & -1.00 & -1.65 & -0.78 & -1.56 & -1.11 & -1.14 & -0.57 \\
\hline $6-311++\mathrm{G}(3 d, 2 p)$ & -1.57 & -1.01 & -1.83 & -0.83 & -1.72 & -1.09 & -1.21 & -0.54 \\
\hline
\end{tabular}


TABLE VII. Dissociation energies $\left(D_{e}\right)$, dissociation enthalpies at $0 \mathrm{~K}\left(D_{0}\right)$ and at $298 \mathrm{~K}\left(-D H_{298}\right)$; cooperativity and three-body effects. All values are in $\mathrm{kcal} / \mathrm{mol}^{\mathrm{a}}{ }^{\mathrm{a}}$

\begin{tabular}{|c|c|c|c|c|c|c|c|c|c|}
\hline & \multicolumn{5}{|c|}{ Previous work } & \multicolumn{4}{|c|}{ Cooperativity } \\
\hline & $D_{e}$ & $D_{0}$ & $-\Delta H_{298}$ & Theory & Expt & $D_{e}$ & $D_{0}$ & $-\Delta H_{298}$ & $-\Delta E_{3}$ \\
\hline $\mathrm{M}_{2} \mathrm{~T}$ & 18.94 & 16.16 & 15.92 & & & 1.40 & 1.94 & 2.50 & 2.34 \\
\hline $\mathrm{T}_{2} \mathrm{M}$ & 17.05 & 14.82 & 14.25 & & & -0.24 & 0.37 & 0.65 & 1.95 \\
\hline $\mathrm{T}_{3}$ & 11.57 & 9.80 & 8.86 & $8.1^{\mathrm{b}}$ & & -2.71 & -1.93 & -1.31 & 1.56 \\
\hline $\mathrm{M}_{3}$ & 15.34 & 11.84 & 12.27 & $11.52^{\mathrm{c}}$ & $12.5^{\mathrm{d}}$ & 0.22 & 0.80 & 2.10 & 2.34 \\
\hline $\mathrm{M}_{2}$ & 5.34 & 3.98 & 3.70 & $3.55^{\mathrm{c}}$ & $3.2^{\mathrm{e}}-3.5^{\mathrm{f}}$ & & & & \\
\hline $\mathrm{T}_{2}$ & 5.04 & 4.19 & 3.67 & $3.09^{\mathrm{b}}$ & & & & & \\
\hline $\mathrm{TM}$ & 10.64 & 9.39 & 9.13 & & & & & & \\
\hline MT & 2.27 & 1.53 & 1.46 & & & & & & \\
\hline
\end{tabular}

${ }^{a}$ Values are calculated at the MP2/6-311++G(3d,2p) level for dimers and heterodimers, and at the MP2/6-311 $++\mathrm{G}(d, p)$ for trimers and heterotrimers. Cooperativity and three-body effects are obtained at the $\mathrm{MP} 2 / 6-311++\mathrm{G}(d, p)$. The scaled B3LYP/6-311++G( $d, p)$ frequencies are used for zero-point energy and thermal corrections.

${ }^{\mathrm{b}}$ Reference 23.

${ }^{\mathrm{c}}$ Reference 13.

${ }^{\mathrm{d}}$ Reference 44.

${ }^{\mathrm{e}}$ Reference 11

${ }^{\mathrm{f}}$ Reference 43.

plexes using the full counterpoise correction procedure. The results are displayed in Table VIII. It can be seen that the BSSE at the MP2 level is much larger (by a factor of up to 2.7) than that at the HF level. It is also apparent that the BSSE at the B3LYP level is very similar to that estimated at the HF level. The BSSE is reduced by increasing the size of the basis set. For instance, the BSSE for $\mathrm{M}_{2}$ at the $\mathrm{MP} 2 / 6-311++\mathrm{G}(d, p)$ amounts to $37 \%$ of the interaction energy, while at the MP2/6-311++G(3d,2p) the BSSE amounts to $18 \%$ of the interaction energy.

It is important to mention that the BSSE affects the geometries (distances and angles) of the hydrogen-bonded systems. Even though we did not correct the optimized O...O distances for BSSE, we should expect the uncorrected O...O equilibrium distance to be somewhat shorter than the corresponding BSSE-corrected calculations. This is because in an $A B$ system the energy lowering of $A$ by using $B$ 's basis functions is helped by bringing $B$ closer to $A$.

\section{CONCLUSIONS}

This paper is, to our knowledge, the first ab initio study of hydrogen bonding and cooperativity of mixed dimer and trimer clusters of methanol and trifluoromethanol. The results were compared with those of the corresponding dimers and trimers of each molecule, i.e., $\mathrm{CF}_{3} \mathrm{OH}$ and $\mathrm{CH}_{3} \mathrm{OH}$. The structures were systematically optimized, and harmonic vibrational frequencies were calculated from analytical second derivatives.

Dimerization and trimerization caused noticeable shifts in the frequencies of many vibrational modes. Not surprisingly, those involving the $\mathrm{O}-\mathrm{H}$ bond were most dramatically affected. The donor character of $\mathrm{CF}_{3} \mathrm{OH}$, as indicated by the $\mathrm{O}-\mathrm{H}$ frequency shifts, is more evident in the TM system than in $\mathrm{T}_{2}$. The shifts of the $\mathrm{O}-\mathrm{H}$ stretching and torsion frequencies in the mixed trimers are much larger than in the trimers and mixed dimers.

TABLE VIII. Basis set superposition error (BSSE) at the HF, MP2, and B3LYP levels of theory and different basis sets. ${ }^{\text {a }}$

\begin{tabular}{|c|c|c|c|c|c|c|c|c|c|c|}
\hline & \multicolumn{3}{|c|}{$\mathrm{M}_{2}$} & \multicolumn{3}{|c|}{$\mathrm{T}_{2}$} & \multicolumn{2}{|c|}{$\mathrm{M}_{3}$} & \multicolumn{2}{|c|}{$\mathrm{T}_{3}$} \\
\hline & $\mathrm{HF}$ & MP2 & B3LYP & $\mathrm{HF}$ & MP2 & B3LYP & $\mathrm{HF}$ & MP2 & $\mathrm{HF}$ & MP2 \\
\hline $6-311++\mathrm{G}(d, p)$ & 0.69 & 1.86 & 0.78 & 0.86 & 1.92 & 0.74 & 1.55 & 4.37 & 1.93 & 4.27 \\
\hline $6-311++\mathrm{G}(2 d, 2 p)$ & 0.43 & 1.11 & 0.42 & 0.92 & 1.80 & 0.76 & & & & \\
\hline \multirow[t]{3}{*}{$6-311++\mathrm{G}(3 d, 2 p)$} & 0.27 & 0.94 & 0.27 & 0.69 & 1.45 & 0.87 & & & & \\
\hline & \multicolumn{3}{|c|}{$\mathrm{TM}$} & \multicolumn{3}{|c|}{ MT } & \multicolumn{2}{|c|}{$\mathrm{T}_{2} \mathrm{M}$} & \multicolumn{2}{|c|}{$M_{2} T$} \\
\hline & $\mathrm{HF}$ & MP2 & B3LYP & $\mathrm{HF}$ & MP2 & B3LYP & $\mathrm{HF}$ & MP2 & $\mathrm{HF}$ & MP2 \\
\hline $6-311++\mathrm{G}(d, p)$ & 0.97 & 2.50 & 1.05 & 0.52 & 1.20 & 0.54 & 2.00 & 5.09 & 1.85 & 5.07 \\
\hline $6-311++\mathrm{G}(2 d, 2 p)$ & 0.69 & 1.73 & 0.65 & 0.52 & 1.00 & 0.44 & & & & \\
\hline $6-311++\mathrm{G}(3 d, 3 p)$ & 0.48 & 1.57 & 0.50 & 0.33 & 0.75 & 0.35 & & & & \\
\hline
\end{tabular}

${ }^{\mathrm{a}} \mathrm{HF}$ interaction energies (BSSE corrected) for the trimers are $-12.28,-8.85,-14.54$, and $-16.28 \mathrm{kcal} / \mathrm{mol}_{\text {for }} \mathrm{M}_{3}, \mathrm{~T}_{3}, \mathrm{~T}_{2} \mathrm{M}$ and $\mathrm{M}_{2} \mathrm{~T}$, respectively. 
Cooperative effects were also evidenced by shorter O...O distances, increased donor $\mathrm{O}-\mathrm{H}$ bond lengths, enhanced dipole moments, and charge densities computed at the bond critical points. Dissociation enthalpies at $0 \mathrm{~K}$ and at room temperature were also used to measure cooperativity. Threebody effects were explored as an alternative way of measuring quantitatively cooperative effects.

Our results indicate that the strength of the hydrogenbonding interaction, in the various clusters studied, follows the order $\mathrm{M}_{2} \mathrm{~T}>\mathrm{T}_{2} \mathrm{M}>\mathrm{M}_{3}>\mathrm{TM}>\mathrm{T}_{3}>\mathrm{M}_{2}>\mathrm{T}_{2}>\mathrm{MT}$. We found the symmetric planar trimers of methanol $\mathrm{M}_{3 s}$ and trifluoromethanol $\mathrm{T}_{3 s}$ to be saddle points of third order. ${ }^{13,23}$

\section{ACKNOWLEDGMENT}

This work was supported by the National Science Foundation and the Office of Naval Research (X.C.Z).

${ }^{1}$ (a) P. Hobza and R. Zahradnik, Chem. Rev. 88, 871 (1988); (b) A. D. Buckingham, P. W. Fowler, and J. M. Hutson, ibid. 88, 963 (1988).

2 (a) S. Scheiner, Hydrogen Bonding: A Theoretical Perspective (Oxford University Press, New York, 1997); (b) E. Clementi and G. Corongiu, in Theoretical Treatment of Hydrogen Bonding, edited by Dušan Hadzi (Wiley, New York, 1997), pp. 265-291.

${ }^{3}$ H. S. Frank and W. Y. Wen, Discuss. Faraday Soc. 24, 133 (1957).

${ }^{4}$ M. C. Shivaglal and S. Singh, Int. J. Quantum Chem. 36, 105 (1989).

${ }^{5}$ W. Weltner and K. S. Pitzer, J. Am. Chem. Soc. 73, 2602 (1961).

${ }^{6}$ G. Larsen, Z. K. Ismail, B. Herreros, and R. D. Parra, J. Phys. Chem. A 102, 4734 (1998).

${ }^{7}$ M. W. Feyereisen, D. Feller, and D. A. Dixon, J. Phys. Chem. 100, 2993 (1996).

${ }^{8}$ O. Mó, M. Yáñez, and J. Elguero, J. Chem. Phys. 97, 6628 (1992).

${ }^{9}$ E. H. S. Anwander, M. M. Probst, and B. M. Rode, Chem. Phys. 166, 341 (1992).

${ }^{10}$ A. Bleiber and J. Sauer, Chem. Phys. Lett. 243, 238 (1995).

${ }^{11}$ A. Bizzarri, S. Stolte, J. Reuss, J. G. C. M. V. D.-V. D. Rijdt, and F. B. V. Duijneveldt, Chem. Phys. 143, 423 (1990).

${ }^{12}$ O. Mó, M. Yáñez, and J. Elguero, J. Mol. Struct.: THEOCHEM 314, 73 (1994).

${ }^{13}$ O. Mó, M. Yáñez, and J. Elguero, J. Chem. Phys. 107, 3592 (1997).

${ }^{14}$ F. C. Hagemeister, C. J. Gruenloh, and T. S. Zwier, J. Phys. Chem. 102, 82 (1998).

${ }^{15}$ N. Bakkas, Y. Bouteiller, A. Louteiller, J. P. Perchard, and S. Racine, J. Chem. Phys. 99, 3335 (1993).

${ }^{16}$ S. Arulmozhiraja and P. Kolandaivel, J. Mol. Struct.: THEOCHEM 366, 123 (1996).

${ }^{17}$ L. Schriver and A. Burneau, J. Chem. Soc., Faraday Trans. 1 81, 503 (1985).

${ }^{18}$ A. Burneau, Spectrochim. Acta A 45, 1305 (1989).

${ }^{19}$ W. A. P. Luck and S. Peil, J. Mol. Struct.: THEOCHEM 224, 185 (1990).
${ }^{20}$ L. Schriver, A. Schriver, S. Peil, and O. Schrems, Can. J. Chem. 69, 1520 (1991).

${ }^{21}$ Y. Mizutani, K. Kamogawa, T. Kitagawa, A. Shimizu, Y. Tanigushi, and K. Nakanishi, J. Phys. Chem. 95, 1790 (1991).

${ }^{22}$ J. Marco, J. M. Orza, and J.-L. M. Abboud, Vib. Spectrosc. 6, 267 (1994).

${ }^{23}$ W. E. Doering, R. D. Parra, and X. C. Zeng, J. Mol. Struct.: THEOCHEM 431, 119 (1998).

${ }^{24}$ T. J. Wallington, M. D. Hurley, and W. F. Schneider, J. Phys. Chem. 97, 7606 (1993)

${ }^{25}$ W. F. Schneider and T. J. Wallington, J. Phys. Chem. 97, 12783 (1993).

${ }^{26}$ L. J. Chyall and R. Squires, J. Phys. Chem. 100, 16435 (1996).

${ }^{27}$ R. L. Asher, E. H. Appelman, J. L. Tilson, M. Litorja, J. Berkowitz, and B. Ruscic, J. Chem. Phys. 106, 9111 (1997).

${ }^{28}$ M. J. Frisch, G. W. Trucks, H. B. Schlegel, P. M. W. Gill, B. G. Johnson, M. A. Robb, J. R. Cheeseman, T. Keith, G. A. Petersson, J. A. Montgomery, K. Raghavachari, M. A. Al-Laham, V. G. Zakrzewski, J. V. Ortiz, J. B. Foresman, J. Ciolowski, B. B. Stefanov, A. Nanayakkara, M. Challacombe, C. Y. Peng, P. Y. Ayala, W. Chen, M. W. Wong, J. L. Andres, J. S. Binkley, D. J. Defrees, J. Baker, J. P. Stewart, M. Head-Gordon, C. Gonzales, and J. A. Pople, Gaussian 94 (Rev. E.2), Gaussian, Inc., Pittsburgh, PA, 1995.

${ }^{29}$ M. J. Frisch, G. W. Trucks, H. B. Schlegel, G. E. Scuseria, M. A. Robb, J. R. Cheeseman, V. G. Zakrzewski, J. A. Montgomery, Jr., R. E. Stratman, J. C. Burant, S. Dapprich, J. M. Millam, A. E. Daniels, K. N. Kudin, M. C. Strain, O. Farkas, J. Tomasi, V. Barone, J. Ochterski, G. A. Peterson, P. Y. Ayala, Q. Cui, K. Morokuma, D. K. Malick, A. D. Rabuck, K. Raghavachari, J. B. Foresman, J. Cioslowski, J. V. Ortiz, B. B. Stefanov, G. Liu, A. Liashenko, P. Piskorz, I. Komaromi, R. Gomperts, R. L. Martin, C. Gonzales, M. Challacombe, P. M. W. Gill, W. Chen, M. W. Wong, J. L. Andres, C. Gonzales, M. Head-Gordon, E. S. Replogle, and J. A. Pople, GAussian 98 (Revision A3), Gaussian, Inc., Pittsburgh, PA, 1998.

${ }^{30}$ A. D. Becke, J. Chem. Phys. 98, 5648 (1993).

${ }^{31}$ S. S. Xantheas, J. Chem. Phys. 102, 4505 (1995).

${ }^{32}$ D. A. Estrin, L. Paglieri, G. Corongui, and E. Clementi, J. Phys. Chem. 100, 8701 (1996).

${ }^{33}$ S. Fredericks, K. D. Jordan, and T. S. Zwier, J. Phys. Chem. 100, 8701 (1996).

${ }^{34}$ G. Fitzgerald, C. Lee, and H. Chen, J. Chem. Phys. 101, 4472 (1994).

${ }^{35}$ J. E. Del Bene, W. B. Person, and K. Szczepaniak, J. Phys. Chem. 100, 7810 (1995)

${ }^{36}$ J. J. Novoa and C. Sosa, J. Phys. Chem. 99, 15837 (1995).

${ }^{37}$ P. Süle and Á. Nagy, J. Chem. Phys. 104, 8524 (1996).

${ }^{38}$ L. Gonzales, O. Mó, M. Yáñez, and M. Elguero, J. Mol. Struct.: THEOCHEM 371, 1 (1996).

${ }^{39}$ C. W. Bauschlicher, Jr., Chem. Phys. Lett. 246, 40 (1995).

${ }^{40}$ R. F. W. Bader, Atoms in Molecules: A Quantum Theory (Oxford University Press, New York, 1990).

${ }^{41}$ S. F. Boys and F. Bernardi, Mol. Phys. 19, 553 (1970).

${ }^{42}$ F. Huisken, M. Kaloudis, M. Koch, and O. Werhahn, J. Chem. Phys. 105, 1 (1996).

${ }^{43}$ L. A. Curtiss and M. Blander, Chem. Rev. 88, 827 (1988).

${ }^{44}$ E. E. Tucker, S. B. Farnham, and S. D. Christian, J. Phys. Chem. 73, 3820 (1969) 